\title{
Traditions and Transitions in Teacher Education: The Development of a Research Project
}

\section{Sandra Acker}

A group of sociologists and historians is studying transitions in teacher education over time, in Ontario, Québec, and Saskatchewan, mainly by analysing experiences of faculty who lived and worked through them. 'T The project began in 1999 with Sandra Acker as Principal Investigator and with four co-investigators, Elizabeth Smyth, Thérèse Hamel, Dianne Hallman, and Jo-Anne Dillabough. The research has these chief purposes:

- to describe and to compare effects on faculty of institutional transitions in teacher education in the three provinces from 1945 to the present;

- to detail these transitions through case studies of selected institutions in Ontario, Québec, and Saskatchewan;

- to trace the policy trajectory (Ball, 1997) of the development of a research culture in each site; and

- to extend the literature on Canadian teacher education by reporting findings in a monograph.

Those purposes led to the questions that guide the study: What factors produce transitions in teacher education? What effects do transitions have on the careers and outlooks of faculty members? Do the transitions parallel the development of a research culture and changes in what counts as research? Are the transitions systematically associated with changes in characteristics, qualifications, responsibilities, divisions of labour, and programs of research among faculty?

Although there are published historical accounts of Canadian education faculties, few are critical and almost none deal with the teacher education professoriate. In fact, there is a surprisingly general absence of historical and sociological research on teacher educators. ${ }^{2}$ I here describe the background to our project, and trace the reasons why our research has taken the shape it has. I also review two earlier projects that influenced our purposes and design, for our research depends upon and is influenced by work that has preceded it.

'Thanks to faculty colleagues and others who have worked on the project, namely Heather Alpert, Jo-Anne Dillabough, Dianne Hallman, Thérèse Hamel, Nicole Sanderson, Elizabeth Smyth, and Barbara Soren.

2Exceptions in Canada include Acker, 1997; Cole, 1999; Weber, 1986, 1990. 
KEY CONCEPTS

\section{Transitions}

The concept "transitions" refers to changes that significantly affected institutions and individuals. These are "critical moments" or "moments de rupture," key dates when "something happened" that altered the course of institutional history. The most important long-term shift in Canada was teacher education's gradual move from normal schools and teachers' colleges into the universities (Hamel, 1991; Sheehan \& Wilson, 1994; Wideen \& Hopkins, 1983). Each province made this transition in its own time and its own way, with movement into universities beginning after World War II and accelerating in the 1960s and 1970s (Johnson, 1966). Factors as various as government policies, economic fortunes, political pressures, university politics, and the activities of ambitious administrators have triggered transitions in specific sites. These changes take such forms as restructuring in faculties, physical moves, and new internal governance and financial mechanisms (Fenstermacher, 1995). The project takes particular interest in recovering the stories of faculty members who experienced these transitions.

The justification for the move into universities usually revolved around the production of a higher quality and more professional teaching force (Hamel, 1995). Yet teachers' college staff, who became university teachers by default, were often under-qualified for a university position (Fullan \& Connelly, 1987, 11). Calam $(1981,281)$, although sceptical of romanticized views of the normal school, notes that the movement of teacher education into the universities was not an "unmitigated advance" given the "professional and political friction" that followed the merging of two cultures. Amalgamation produced a sense of separation from the rest of the university, which only grudgingly provided resources and respect to teacher education (Fullan, 1993; Wideen \& Hopkins, 1983). As new faculty were hired, they had increasingly to meet the twin expectations of demonstrated past competence in school teaching and an ability to pursue university research.

\section{Research Culture}

The research team believes these transitions have been accompanied, if not driven, by the spread of the research culture or "research imperative" (Gumport, 1991). Writing about the United States, Gumport argues that "universities embrace the research imperative as a vehicle for upward mobility in the national hierarchy of academic institutions." (87) Although the Canadian university does not duplicate the complex stratification of American universities, there are status distinctions among institutions and among units within universities. Many departments and faculties that in the past concentrated on pre-service and in-service teacher certification have increased their research emphasis through a range of mechanisms, including strategic faculty renewal and the initiation or expansion of graduate studies. For education faculties at the century's turn, the research imperative comes from competition for scarce resources, desire to gain status, and a tendency evident in many countries to enforce greater productivity and accountability in universities. 
Using an approach developed by researchers in Britain, we conceptualize the spread of the research imperative as a "policy trajectory" (Ball, 1993, 1994, 1997; Bowe \& Ball with Gold, 1992). Studying a policy trajectory entails tracing a specific reform initiative over time, examining its origins and the factors that have sustained it, and detailing how individuals and groups have resisted and altered it. In the field of teacher education, the policy trajectory of "increased attention to research" may have its own particular parameters. This trajectory could well be rooted in the supposed inadequacies of the early institutional forms of teacher education and the strategies of reformers to improve the status of these institutions by aligning them more closely with the scholarly enterprise. At the same time, there are strong traditions in teacher education of exceedingly heavy workloads, in part as a consequence of a caring ideology towards students regardless of the time needed to pursue it (Howey \& Zimpher, 1989; Patterson, 1979; Watson \& Allison, 1992).

In any workplace, patterns of belief, values, symbols, language, right and wrong ways of doing things arise (such as that caring ideology) that can be called a workplace culture (Acker, 1999). When structures alter radically, as when a teachers' college becomes a university faculty, or two institutions merge, workplace cultures have a major, if paradoxical, role. Although they help people understand, interpret, and respond to events, they can provide a focus for resistance to change and make it more difficult for individuals to adapt. If the change is to be accomplished, there must be a certain "reculturing" (Fullan, 1996). Yet enthusiastically to embrace "reculturing" is tantamount to admitting faults in one's past culture.

Our research seeks to document the development and spread of the research culture and its consequences and contradictions for faculty and administrators. We intend to provide what Stake $(1994,237)$ calls a collective case study, a comparison of cases in order to advance theoretical understanding of a phenomenon. Although we recognize, and where possible describe, macrosociological and broader historical trends, we concentrate on the microsociological, seeking the interpretations and strategies of those who experienced the transitions and the consequent reverberations within the cultures of their workplaces.

\section{ANTECEDENTS OF THE PROJECT}

\section{WOMPROF}

The most important influence on the "Transitions" project was probably the network "Women and Professional Education" (or WOMPROF), funded by the Social Sciences and Humanities Research Council of Canada (SSHRC). Alison Prentice, then at Ontario Institute for Studies in Education of the University of Toronto (OISE/UT), was the Principal Investigator for WOMPROF. From 1995 to 1999, the network brought 14 or 15 scholars together for yearly meetings, supplemented by e-mail communication. At each meeting, participants reported 
on their individual research, shaping and extending it a little further each time. It was a productive model for sharing and developing research. Four participants at OISE/UT, Elizabeth Smyth, Sandra Acker, Paula Bourne, and Alison Prentice, took responsibility for editing a book resulting from the network, Challenging Professions: Historical and Contemporary Perspectives on Women's Professional Work (Smyth, Acker, Bourne, \& Prentice, 1999).

The network consisted mostly of historians and a few sociologists, including myself. We discovered how pleasant it could be to work across disciplinary divides. In the final phase of the network, additional scholars including Thérèse Hamel and Dianne Hallman (both trained in sociology and history) joined the group. About the same time, Jo-Anne Dillabough, a sociologist, came to OISE/UT from Cambridge, England. Sandra Acker, Elizabeth Smyth, Thérèse Hamel, Dianne Hallman, and Jo-Anne Dillabough decided to take the collaboration of historians and sociologists a stage further and developed the proposal for research on traditions and transitions in teacher education, with Sandra Acker as Principal Investigator. (The network itself took a new form in the Research Group on Women and Professional Education, facilitated by Ruby Heap at University of Ottawa.)

\section{$M A D$}

Also in 1995-1999, I was Principal Investigator for a SSHRC-funded strategic grant project called "Making a Difference" (MAD). It was a study of academics in the four professional fields of social work, education, pharmacy and dentistry, conducted by a team of five academics. ${ }^{3}$ The main purpose of the study was to address the consequences for academic women of the trend towards feminization of the professions and professional education. Numbers of women faculty have risen in recent years, but not to the extent found in the student body. Consequently, the investigators reasoned that women academics may be under more pressure to be sponsors and role models, whereas their own experience remains one of marginality. On the other hand, the increased presence of women, together with the spread of feminist scholarship, might bring about some change in the university and ultimately the professions.

The four fields form a continuum with social work having the greatest representation of women students and dentistry the least. The study aimed to fill neglected middle ground between surveys and accounts of individual experience, probing the processes of academic life and the perceptions and interpretations of those who live it, meanwhile building a picture of the policies and practices that make the academic environment a gendered workplace. It was a qualitative study, informed by symbolic interactionist sociology and by feminism.

${ }^{3}$ My thanks to Carol Baines, Marcia Boyd, Grace Feuerverger, and Linda Muzzin, who worked on the MAD project, as well as to the Social Sciences and Humanities Research Council for making the three funded projects described in this article possible. 
Interviews were semi-structured and usually lasted from 60 to 90 minutes, in most cases done by faculty members on the research team. Each colleague had a close connection with one of the fields under study. We asked participants about experiences with hiring, tenure and promotion, feelings of centrality or marginality, incidents of discrimination or harassment, and teaching, research, and other work responsibilities. We also inquired about the ethos or culture of the department and faculty, the interface of home and work, health and stress, and future career plans.

My own participation had most to do with the field of education. In 19951996 we conducted 68 interviews ( 10 in French, the rest in English) with 43 women and 25 men in the field of education, spread across five universities in four provinces and the three tenure-track ranks of assistant, associate, and full professor.

There are a number of interesting results that can only be mentioned here. For example, preoccupations of the women academics in education faculties included: 1) juggling home and work; 2) overload; 3) evaluation (tenure, promotion, merit); 4) stress and health; 5) relationships with colleagues and students; and (in some institutions) 6) restructuring and uncertainty. One of the most interesting themes was "overload." Many of the women believed they worked much harder than their male colleagues, seeing themselves taking an unfair share of responsibilities for nurturing students and doing the "housekeeping" work in their departments. This theme is explored in two publications entitled "Doing Good and Feeling Bad" (Acker \& Feuerverger, 1996) and "Enough Is Never Enough" (Acker \& Feuerverger, 1997).

Several themes from the MAD study, especially its education component, contributed to the current project. Of these, three are particularly important: generational differences; histories of the institutions; and divided allegiances.

\section{Generational Differences}

One aspect of the experience of women teacher educators, in particular, that stood out was the differences among cohorts or generations. In the article "Becoming a Teacher Educator," (Acker, 1997) I presented five case studies that demonstrated variations on the process of recruitment into academic life. The older women told stories about how "the dean came knocking at my door" asking if they would come and join the faculty, while the younger ones had to be credentialed with doctorates and then to compete for scarce positions. The most common pattern from the 1970 s onwards was for the women first to be teachers, next to acquire a doctorate (or be almost there), and then to enter academic life. There were always exceptions, such as women with little or no school-teaching experience who went into sociology or psychology or other foundations areas of education.

I found the two extremes (in age-related terms) the most interesting. Women hired in the 1960s were near the end of their careers. Some had only recently achieved full professorships. There were few women full professors in these 
university faculties of education, and almost all at this rank had acquired it in the 1990s. In older women's stories, it was striking how far they had to re-invent themselves as the rules of the game changed. (Of course, the people who could not accomplish this feat probably were not there to be interviewed.) Iris's interview was particularly compelling for me, and I shall use excerpts to illustrate my points.

Iris did not say, as another participant did, that the dean knocked on her door, but her hiring was similarly casual:

I started off being a [subject] teacher ... I was invited to join the faculty of education, the first year as a seconded teacher and then after that I was invited to join the faculty full time, and I've been here ever since.

She had not planned on becoming an academic:

Sandra: When did you realize you were becoming an academic? Did you think oh I'm going to be an academic now?

Iris: No, I didn't pursue the job at the university. I just got a phone call one day, late May I guess it was, from the university asking me if I'd be interested in coming to the university for a year to teach. And I was honoured, shall we say, and scared at the same time ... and then I had the opportunity to stay, and it was then that I started down the road of becoming an academic. But I hadn't at that stage pursued it and I hadn't actually I don't think envisioned myself being a professional all my life. I think I had more the idea of teaching for a few years and then becoming a traditional housewife/ mother and that type of thing.

At the time she was hired, she had a master's degree, fairly typical in her cohort. Like others, she had to figure out how to do a doctorate when it appeared career options would be limited without it:

I had my master's degree when I started, then I did my doctoral degree sort of along the way while I was already a faculty member here. So I sort of interrupted my teaching for awhile and did my doctoral degree at the same time as trying to do some teaching. ... I took, I guess, one year leave of absence but I did my doctoral, I got special permission to do my doctorate at [this university] but in [subject field] while I was teaching in education and it took a little bit of juggling, and, you know, special conditions and what not, but it enabled me to stay in [city] with my family and everything and retain my job while getting my $\mathrm{PhD}$.... I spent about two thirds of my career with just sort of the masters degree and then saw the writing on the wall [laughter] and decided to pursue the doctorate degree.

In the younger cohorts, the stories were dominated by the stresses of coming up to expectations, which seemed to be ever on the rise. Tenure, promotion, and merit reviews loomed large in all the interviews, although for older academics, tenure had not generally been a problem, though promotion might have been. Everyone detested annual reviews for the purpose of assigning merit-based salary increases. The older women were concerned about the pressure on their junior colleagues. For example, when I asked Iris what her experiences were with tenure and promotion, she responded:

Well, tenure was a long time ago and under very different rules than it is these days ... at that time I got my tenure after seven years as an assistant professor, and it certainly wasn't the hassle then that it is now for people to get tenure. I know everybody sort of worry, worry, worries whether they're going to get it or not, and I can't recall worrying about it. I assumed it was just something that happened, and 
as long as you taught well and did your job well it was kind of automatic in those days, whereas now the anxiety level I know among junior faculty is extreme to the point that they worry, worry, worry and then when they finally get it, it's sort of a major relief.

These interviews got me thinking about the "research culture" and how it had developed over time. Iris talked about how the rules had changed, for promotion as well as tenure:

I started as an associate professor in one set of rules and then the rules got changed ... At the time when I should have come up for promotion to a full professor, all the criteria got shifted around and a major emphasis then on research and publications and how many grants have you got and what not.... Within a few years, all of that seemed to have got shifted around and it was at the point when I was doing my doctoral work and therefore my interest was elsewhere, so when I came back, and you know, thought I'd be getting [promoted], in the promotion thing all the rules had changed, so I basically had to start from scratch and be qualified for that promotion again. It was distressing and stressful. I asked Iris what the criteria now were for promotion to full professor. Note in her response how women might have been disadvantaged if they had concentrated on a family rather than going to conferences:

Well, you're supposed to have an international reputation: all of your records have to go out and be critiqued by people all over the place, and these have to recognized scholars, and if you happened to have not gone to, say for a period of time because I had a family and I didn't go to a whole lot of international conferences, therefore you don't get that international exposure. So there's that kind of a problem, and it never occurred to me that I should be deliberately trying to cultivate international contacts... And you're supposed to have, you know, a huge stack of articles in all the prestigious journals, first author of course on all of them, [and] you're supposed to have x number of grants and graduate students and have this international reputation and be able to chose referees that are going to give you good comments back. So it's tricky, shall we say, and it takes time and sometimes probably people are more concerned with getting promoted than with becoming a good scholar.

\section{Histories of the Institutions}

Contained in some of the interviews were references to the changes in the institutions themselves. A few of the older participants had worked in teachers' colleges before becoming university faculty members or had observed the integration of faculty from one institution into another. In this section I will use extracts from an interview with an academic I call Charles. Charles explained:

The basis of the Faculty of Education was the original teachers' college, which had been established in the [date].... provincial teachers' college until [date] when it was merged with the university as the faculty of education. [Originally] it had only elementary school teaching programs. In [date] it added the secondary school teaching programs and I'd say about [date] it added graduate studies.

Charles came into the university when the secondary program started: "There are three of us left, and so as the faculty's evolved it has lost all, now has none of the original teachers' college staff here." 
Charles's faculty, like others, has shifted towards incorporating research into its mission and upgrading the educational qualifications of the faculty: "In the last eight to ten years, we've had a very good turnover or renewal, with faculty almost all with doctorates, which the university has considered an advantage." $\mathrm{He}$ thinks that "We've certainly changed the look of the place by the change in faculty, so there's much more activity in research of various types... we have one of the most active research or scholarly groups [in the university]." Charles believes that unlike some other institutions, this university has respect for its faculty of education:

Yeah, there certainly has been that [looking down on education] here and there may still be some, but I think the quality of the students and the faculty changes in the last decade have had quite positive effects.

Charles has found his niche as an administrator, but as one of the veteran members of the faculty, he has not become active in research. When asked "Do you have any research interests?" he replied:

No, I don't have any activity in research; I mean there's just a limit....and it wasn't my forte when I came... I was coming out of teaching ranks of the high schools and so on, back in the ... tradition then, so while I have done some [research], it wasn't something I came up with, and indeed, I don't have a doctorate, so I don't have that, didn't come from that side of things or [have] some blend, which is now more common.

Today's faculties of education continue to display an uneasy relationship between the (sometimes) competing functions of preparing teachers and advancing knowledge through research (Clifford \& Guthrie, 1988; Cuban, 1999; Tom, 1997).

\section{Divided allegiances}

Characteristic of all of the four fields in the MAD study were multiple pressures from different directions. Each field seemed to have some kind of divide, for example between clinical and scientific specialties, or theory and practice. In faculties of education, it was clear that training teachers could be pitted against teaching graduate students and doing research. Additionally there were possibilities of doing in-service and outreach work.

Participants universally complained about their work loads, convinced they were higher than those carried by persons in other parts of the university. Who would supervise teacher candidates in the schools was often at issue. Institutions arrived at quite different compromise solutions, ranging from "We all do some of everything" to a clear division of function. In general there was a contrast between the official line and the stories we heard; there was much room for negotiation, and significant tensions between subgroups. Here is Iris again, commenting on these matters:

Iris: So in a sense my teaching is kind of atypical I would say because I've kind of separated and I've done mainly the teacher ed and not done the graduate work, but I'm just sort of getting more and more involved in it. I've done research myself but sort of independently and not with graduate students.

Sandra: What is typical, to move across both? 
Iris: Yeah, yes, particularly junior faculty members-if they don't, in fact I would say that in this institution it's probably much wiser for young faculty to get involved in the grad program than in the teacher ed program. It tends to be a surer way to get promoted, and also it tends to generate articles and research and that type of thing, which the teacher ed program doesn't to the same degree.

These discussions, and my experience of the 1996 merger of the Ontario Institute for Studies in Education and the University of Toronto Faculty of Education, led me to think how the expectations that academics would do "world class research" (as they say at my university) added strain to the lives of education academics. Rather to my surprise, there were aspects of this pressure to do research in all the institutions in our study, not just in the more obvious aspirants to world class status.

\section{THE TEAM}

In designing the current project, I wanted to explore further the development of that pressure for research and how it impacted upon the academics in faculties of education. It seemed to me that such a study would have to be sociological and historical. The MAD study, where individuals specialized in subject areas and would travel across the country to collect data, seemed inappropriate as a model for the next project. It ought, instead, to be more readily divisible, in the sense that each person would have responsibility for a geographical area. WOMPROF participants were ideal candidates for this plan.

A number of us had common interests in teachers, teacher education, and gender. Elizabeth Smyth had specialized in the study of women religious who are teachers, including the teacher education provided for and by these individuals. At the time, she was working at the OISE/UT field centre in Thunder Bay and so could add a Northern Ontario perspective to the study. Thérèse Hamel's previous SSHRC project, "L'évolution de la formation des maîtres au Québec 1939 à nos jours," is directly relevant to the new project. Thérèse had studied the history of teacher training and the normal schools in Québec, including autobiographical writings of social actors who lived through the abolition of the normal schools. We would thus "cover" Ontario and Québec. As good things come in threes, it seemed that we should have at least one other province represented. Dianne Hallman was ideal for the task, currently working at the University of Saskatchewan, and sharing my interest in women teachers. Finally, Jo-Anne Dillabough appeared in 1998 like a gift from afar, to complete the team. While a SSHRC postdoctoral fellow working in the United Kingdom, she had been conducting research on the impact of educational restructuring on the conditions of women teacher educators' work.

The plan for the current study involved several phases. Briefly, we would begin by investigating documentary sources as well as secondary literature about teacher education in each province. The documentary evidence would be extended and complemented by mini-case studies based on two or three-day visits to several faculties in each province, where we would interview some key individuals and also collect documentation. The third phase would be a major case study of one or two 
institutions in each province, where both retired faculty and current faculty would be interviewed to determine what their experiences of transitions had been and how it had affected them.

\section{CONCLUSION: SENSE AND SERENDIPITY}

As with much qualitative research, we find that the design is being modified as we go along, for personal, professional and research-related reasons. All of us experienced major and unexpected changes in our personal or work lives. For example, I became a department chair, Elizabeth moved to Toronto, Jo-Anne had a baby - and the pace of the research had to accommodate these changes. The three of us in Ontario are debating the balance between the mini-case study model and the case-study approach, considering our energy, our resources, and ideas from the first set of interviews. For the mini-case studies, we find that two or three interviews with key figures, plus some reading of relevant documents or institutional histories, produce enough for a portrait of a faculty. References interviewees make to other faculties, showing similarities or differences, lead us to want to make sure we do enough to map the interrelations of institutions in Ontario and beyond (Calam, 1994). ${ }^{4}$ There are also references to the political scene and we are thinking whether we ought to interview or to collect more contextual data.

We see the impact of both planning and serendipity on what becomes research. $\mathrm{Had}$ I not been involved in WOMPROF and MAD, and my colleagues in their various complementary projects, it is unlikely the current research would have taken the form it did, or materialized at all. It is possible the merger in my institution might have triggered an interest in changes in teacher education faculties, but I doubt this by itself would have produced more than mild curiosity. Instead, we have a series of small, accidental, but sometimes incremental events that together constitute an individual's career, joined to serendipity: findings from one project so intriguing that another project is born.

The story is not finished without a mention of other constraints that shape research. Chief among them are funding bodies and funding priorities (Acker, 1994). Had SSHRC not been receptive to research on women through its strategic grant theme on women and change, it is likely that neither WOMPROF nor MAD would have been funded. Similarly, the freedom granted by SSHRC's standard grant process allowed us to create a new proposal in an area that interested us,

'Calam (1994) gives an engaging description of the (literal) lengths to which the President and Dean of Arts and Science went in the search for the first professor for the University of British Columbia Faculty of Education, which opened in the 1923-24 academic year. Not only were the views of eminent academics across the country sought, President Klinck "boarded a train....and set out to confer with as many other referees as a tightly-scheduled, eleven-day search allowed." (187) Calam's account demonstrates the close ties among senior academics at different Canadian universities, as well as noting the involvement of provincial educational officials in the selection of a university faculty member. 
rather than one that could be funded by a corporation or subject to targeted funding.

One off-shoot of our project is international connections. We have managed to stimulate researchers in Sweden and Iceland to design parallel projects and we hope to do the same with colleagues in some other countries. One seasoned researcher in Britain, although personally interested in the topic, did not want to pursue it as she thought the main British funding body in the social sciences would not fund such a project. Teacher education was simply not "hot." Her response reinforces the point that what counts as research is relative in time and place and subject to multiple and changing influences.

Many people involved in higher education are concerned that universities have become too subject to business practices and too dependent on corporate donations. Certainly the under-funding of social science research makes it difficult to get support for many promising projects. Academics in education faculties in the MAD study expressed much frustration with SSHRC, finding it too difficult to get funding for their particular variety of research, perhaps especially those projects that grew out of their field work in the schools. The success of our proposal in receiving funding was no doubt also influenced by the infrastructure and the reward structure of OISE/UT and the University of Toronto.

We have here a project on teacher education and teacher educators that is of necessity reflexive about its antecedents and its context. It is more than a little ironic that we do research on the research imperative. It is not only the subjects in the MAD study who have found evaluation shaping their lives, coming to terms with the complex and contradictory expectations that mark the working lives of teacher educators. Thus a mixture of biography, previous research, institutional sanction, and funding policy shapes our research and that of others.

\section{REFERENCES}

Acker, S. (1994). Gendered Education: Sociological Reflections on Women, Teachingand Feminism. Buckingham: Open University Press.

. (1997). "Becoming a teacher educator: voices of women academics in Canadian faculties of education," Teaching and Teacher Education 13, 1: 65-74.

. (1999). The Realities of Teachers' Work: Never A Dull Moment. London: Cassell/Continuum.

\& Feuerverger, G. (1996). “Doing good and feeling bad: the work of women university teachers," Cambridge Journal of Education 26: 401-22.

\& Feuerverger, G. (1997). "Enough is never enough: women's work in academe," in C. Marshall, ed., Feminist Critical Policy Analysis-A Perspective From Post-secondary Education. London: Falmer Press, 122-40.

Ball, S.J. (1993). "What is policy? Texts, trajectories and toolboxes," Discourse 13, 2 : $10-17$.

. (1994). Education Reform: a Critical and Post-structural Approach. Buckingham: Open University Press.

. (1997). "Policy sociology and critical social research: a personal review of recent education policy and policy research," British Educational Research Journal 23, 3: 257-74. 
Bowe, R., \& Ball, S. (with A. Gold). (1992). Reforming Education and Changing Schools. London: Routledge.

Calam, J. (1981). "Becoming a teacher: some historical perspectives," Alberta Journal of Educational Research 27, 3: 272-84.

(1994). "Teaching teachers on campus: initial moves and the search for UBC's first Professor of Education," Historical Studies in Education 6, 2: 177-200.

Clifford, G.J. \& Guthrie, J. (1988). Ed School. Chicago: University of Chicago Press.

Cole, A. (1999). "Teacher educators and teacher education reform: individual commitments, institutional realities," Canadian Journal of Education 24, 3: 281-95.

Cuban, L. (1999). How Scholars Trumped Teachers: Change Without Reform in University Curriculum, Teaching and Research, 1890-1990. New York: Teachers College Press.

Fenstermacher, G. (1995). "From Camelot to Chechnya: the journey of an education dean," in L. Bowen, ed., The Wizards of Odds: Leadership Journeys of Education Deans, 8-26.

Fullan, M. (1993). Change Forces. London: Falmer Press.

(1996). "Foreword," in D. Booth \& S. Stiegelbauer, eds., Teaching Teachers: the Faculty of Education University of Toronto 1906-1996. Hamilton, Ontario: Caliburn, i-xiv.

. \& Connelly, M. (1987). Teacher Education in Ontario: Current Practice and Options for the Future. Toronto: Ministry of Colleges \& Universities.

Gumport, P. (1991). "The research imperative," in W. Tierney, ed., Culture and Ideology in Higher Education. New York: Praeger, 87-105.

Hamel, T. (1991). Le déracinement des écoles normales: le transfert de la formation des maîtres à l'université. Québec: Institut Québécois de recherche sur la culture (IQRC). . (1995). Un siècle de formation des maîtres au Québec 1836-1939. Québec: Hurtubise-HMH.

Howey, K. \& Zimpher, N. (1989). Profiles of Preservice Teacher Education: Inquiry into the Nature of Programs. Albany, NY: State University of New York Press.

Johnson, F. (1966). "Teacher education in historical perspective," in University of British Columbia Faculty of Education, Teacher education at UBC 1956-1966. Vancouver: UBC Faculty of Education, 17-27.

Patterson, R. (1979). "History of teacher education in Alberta," in C. Jones, N. Sheehan, \& R. Stamp, eds., Shaping the Schools of the Canadian West. Calgary: Detselig, 192-207.

Sheehan, N. \& Wilson, J. (1994). “From normal school to the university to the College of Teachers: teacher education in British Columbia in the 20th century," Journal of Education for Teaching 20, 1: 23-37.

Smyth, E. M., Acker, S., Bourne, P. \& Prentice, A. (1999). Challenging Professions: Historical and Contemporary Perspectives on Women's Professional Work. Toronto: University of Toronto Press.

Stake, R. (1994). "Case studies," in N. Denzin \& Y. Lincoln, eds., Handbook of Qualitative Research. Thousand Oaks, CA: Sage, 236-47.

Tom, A.R. (1997). Redesigning Teacher Education. Albany, NY: State University of New York Press.

Watson, N., \& Allison, P. (1992). Ontario Faculties of Education: Responding to Change. Report prepared for the Ontario Association of Deans of Education, Toronto.

Weber, S. (1986). "Teacher educators: a search for meaning," Elements 18, 1: 22-3.

. (1990). "The teacher educator's experience: generativity and duality of commitment," Curriculum Inquiry 20, 2: 141-59.

Wideen, M., \& Hopkins, D. (1983). A Study of Teacher Training Institutions in Anglophone Canada, Vol. IV: Change in Canadian Teacher Training. Ottawa: SSHRC. 